\title{
Maternal mental health predicts risk of developmental problems at 3 years of age: follow up of a community based trial Suzanne C Tough*1,2,3, Jodi E Siever ${ }^{3}$, Shirley Leew ${ }^{3}$, David W Johnston ${ }^{3}$, Karen Benzies ${ }^{4}$ and Dawne Clark $^{5}$
}

\author{
Address: ${ }^{1}$ Department of Paediatrics, University of Calgary, Calgary, Alberta, T2T 5C7, Canada , ${ }^{2}$ Department of Community Health Sciences, \\ University of Calgary, Calgary, Alberta, T2N 4N1, Canada, ${ }^{3}$ Decision Support Research Team, Calgary Health Region, Calgary, Alberta, T2T 5C7, \\ Canada , ${ }^{4}$ Faculty of Nursing, University of Calgary, Calgary, Alberta, T2N 1N4, Canada and ${ }^{5}$ Child and Youth Studies, Mount Royal College, \\ Calgary, Alberta, T3E 6K6, Canada \\ Email: Suzanne C Tough* - suzanne.tough@calgaryhealthregion.ca; Jodi E Siever - jodi.siever@calgaryhealthregion.ca; \\ Shirley Leew - shirley.leew@calgaryhealthregion.ca; David W Johnston - davidw.johnston@calgaryhealthregion.ca; \\ Karen Benzies - benzies@ucalgary.ca; Dawne Clark -dclark@mtroyal.ca \\ * Corresponding author
}

Published: 6 May 2008

BMC Pregnancy and Childbirth 2008, 8:16 doi:10.1/86/147/-2393-8-16

Received: 21 November 2007

Accepted: 6 May 2008

This article is available from: http://www.biomedcentral.com/I47/-2393/8/16

(C) 2008 Tough et al; licensee BioMed Central Ltd.

This is an Open Access article distributed under the terms of the Creative Commons Attribution License (http://creativecommons.org/licenses/by/2.0), which permits unrestricted use, distribution, and reproduction in any medium, provided the original work is properly cited.

\begin{abstract}
Background: Undetected and untreated developmental problems can have a significant economic and social impact on society. Intervention to ameliorate potential developmental problems requires early identification of children at risk of future learning and behaviour difficulties. The objective of this study was to estimate the prevalence of risk for developmental problems among preschool children born to medically low risk women and identify factors that influence outcomes.
\end{abstract}

Methods: Mothers who had participated in a prenatal trial were followed up three years post partum to answer a telephone questionnaire. Questions were related to child health and development, child care, medical care, mother's lifestyle, well-being, and parenting style. The main outcome measure was risk for developmental problems using the Parents' Evaluation of Developmental Status (PEDS).

Results: Of 791 children, II\% were screened by the PEDS to be at high risk for developmental problems at age three. Of these, $43 \%$ had previously been referred for assessment. Children most likely to have been referred were those born preterm. Risk factors for delay included: male gender, history of ear infections, a low income environment, and a mother with poor emotional health and a history of abuse. A child with these risk factors was predicted to have a $53 \%$ chance of screening at high risk for developmental problems. This predicted probability was reduced to $19 \%$ if the child had a mother with good emotional health and no history of abuse.

Conclusion: Over 10\% of children were identified as high risk for developmental problems by the screening, and more than half of those had not received a specialist referral. Risk factors for problems included prenatal and perinatal maternal and child factors. Assessment of maternal health and effective screening of child development may increase detection of children at high risk who would benefit from early intervention.

Trial registration: Current Controlled Trials ISRCTN64070727 


\section{Background}

The prevalence of developmental disabilities in North America and Australia is estimated between 12\% and 17\% [1-3]. Detection and amelioration of developmental problems in the preschool period increases the likelihood that children enter school ready to learn and succeed $[4,5]$. When developmental problems go undetected and untreated, there is an increased probability of school failure, behaviour problems, low self esteem and loss of potential $[6,7]$. Thus, undetected and untreated developmental problems can have a significant economic and social impact on society.

Intervention to ameliorate potential developmental problems requires early identification of children at risk of future learning and behaviour difficulties. Because physicians and public health nurses are the primary trusted health professionals in routine contact with children under the age of five, they are ideally positioned to screen children and to identify risk of developmental and behavioral problems $[8,9]$. Brief clinical observation is the most commonly used strategy for identifying developmental and/or behavioral problems, however, 50 to $70 \%$ of children are missed by this method, particularly those with less severe delay [1,10-12]. This level of under-detection by primary care providers may result from a lack of recognition of potential risks to development and lack of effective standard screening as well as limited time, resources and remuneration for screening for developmental problems, follow up and referrals $[9,13,14]$.

The implementation of parent-completed screening tools may assist primary care providers in identifying children who would benefit most from early intervention without adding undue burden on providers $[13,15,16]$. In general, parent report has equaled or corresponded to test scores used for identification of developmental problems [17], and parent completed tools have demonstrated validity [14].

Evidence also indicates that child development is influenced by family demographics and lifestyle, such as maternal mental health and income $[8,18,19]$. These are factors that can be identified early on, even prior to birth. Early detection of family, social, and environmental contexts that put children at risk for developmental problems may provide an opportunity to intervene and work with families and communities to create environments that support the optimal development of their children.

Understanding what characterizes at-risk families and children would inform the strategic implementation of community services to support optimal child development. The objectives of this study were to estimate the proportion of children who would screen at risk of devel- opmental problems among preschool children born to medically low risk women, identified by a standardized screening instrument, and to identify parental and environmental factors which were most strongly associated with developmental screening results.

\section{Methods \\ Participants}

Medically low risk women, who participated in a randomized controlled trial of supplementary prenatal care between April 2001 and July 2004 and agreed to future research, were invited to participate in this follow-up study. Low medical risk referred to women who did not require prenatal care from an obstetrician, and had an uncomplicated pregnancy such that specialist care for fetal or maternal complications was not required. Pregnant women who sought services provided by family physicians at one of three participating Calgary maternity clinics were included in the study. Women were excluded from the study if they were under the age of 18 (due to ethical issues associated with confidentiality and informed consent), had not completed the baseline study prior to their first appointment with the clinic, did not plan to attend the clinic at the time of the first recruitment call, lived outside the Calgary Health Region, were not pregnant, or could not communicate to study interviewers or translators in one of seven languages (English, French, Cantonese, Mandarin, Punjabi, Urdu, or Arabic dialects) (Figure 1).

In the original trial, women who participated were randomized to: (1) current standard of prenatal care; (2) standard of care plus support from a nurse; or (3) standard of care plus support from a nurse and home visitor. Study participants completed 3 computer-assisted telephone interviews over the perinatal period (first trimester, 32-34 weeks gestation, and 8 weeks post delivery). Data on demographics, lifestyle, psychosocial health, resource utilization, network orientation, and history of abuse and neglect were collected. Of the 2,556 women who were eligible for the study, 1,737 (68\%) agreed to participate and completed the first questionnaire. Of those who agreed to participate, 78 percent $(1,352 / 1,737)$ completed all three questionnaires. Non-completion rates did not differ by study group, but women who did not complete the study tended to be younger, non-Caucasian and had lower education than those who completed the study. Demographic and lifestyle characteristics did not differ by study group. Overall, 75 percent of women in the study were of Caucasian ethnicity and 73 percent of women had some college or university level education. A full description of the randomized controlled trial and results are reported elsewhere [20]. 


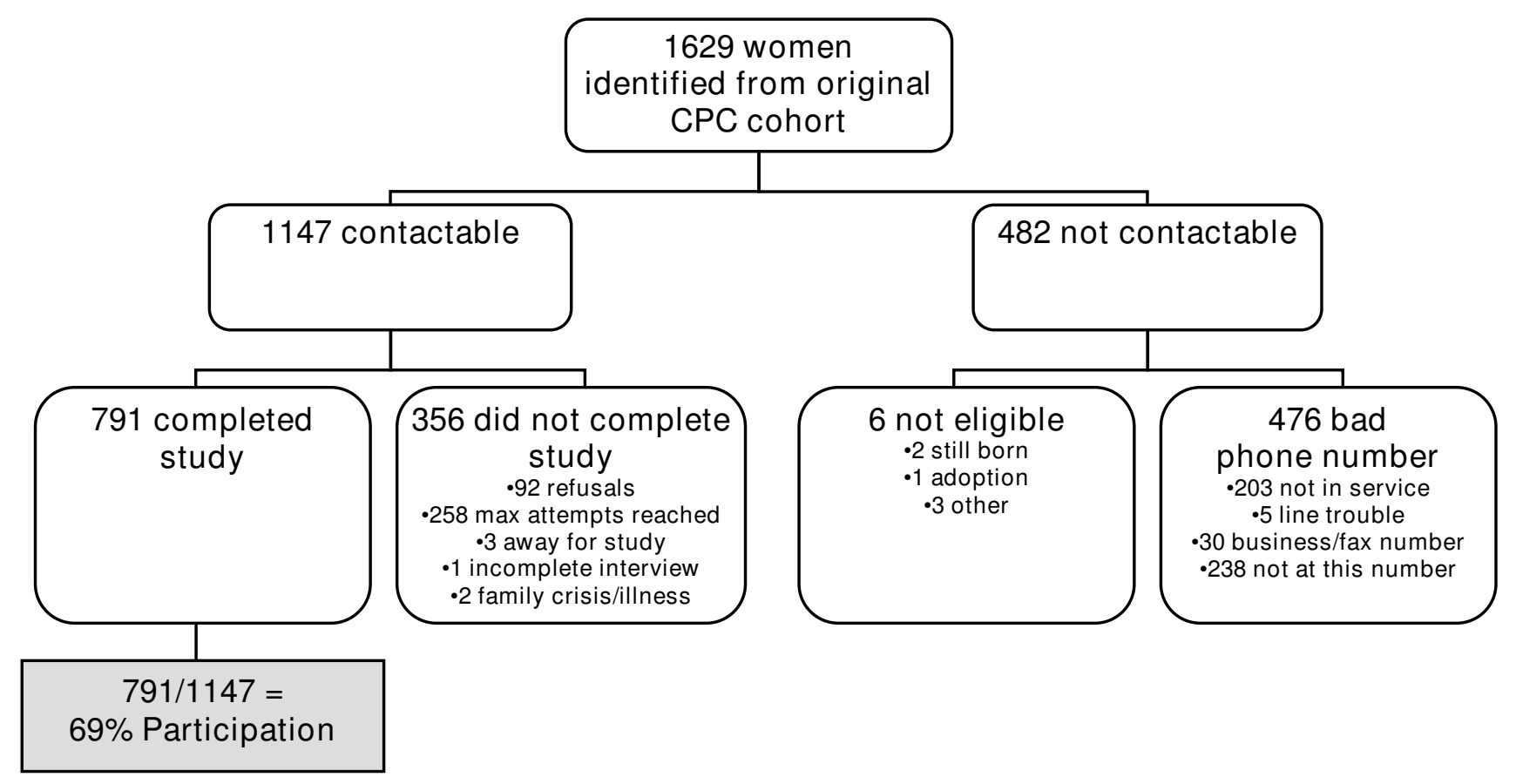

Figure I

Study flowchart mapping eligibility, recruitment, and completion of mothers who participated in the follow up study.

In this follow-up study, mothers were contacted by telephone (using their most recent contact information) when their child was approximately three years old, and they were invited to complete a telephone questionnaire. Before completing the questionnaire, respondents were informed by the interviewers that their participation was voluntary, that their responses would be linked to the original trial data, and that information would be kept confidential. Women who miscarried, did not speak English, did not reside in the city of Calgary any longer, or who had an incorrect phone number were excluded. The follow-up study was launched on November 30, 2005 and was completed on March 27, 2006. The study received ethical approval from the Conjoint Medical Bioethics Committee of the University of Calgary and Calgary Health Region.

\section{Questionnaire}

The telephone questionnaire took approximately 15-20 minutes to complete and included information on child health and medical care, child development, child care, mother's demographics and lifestyle, mother's emotional and physical well-being, and parenting style. Items were generated by the research team in consultation with community partners over a 6 month period at monthly meetings to address the research question and to ensure potential covariates were considered (eg. access to physi- cian services, child care). If an identified construct could be assessed with standardized tools (eg. child development, parenting, social support, detailed below), the research team reviewed and considered appropriate tools and made decisions by consensus. Criteria for tool selection included the psychometric properties of the scale, reading level and length.

The questionnaire was pilot tested with 20 mothers to assess the length, flow, and comprehension. The questionnaire was revised and shortened based on comments from the pilot test as well as expert consultations. Expert consultants included those with backgrounds in: early child development, speech language development, community service delivery, nursing, social work, epidemiology, survey development, biostatistics, and parenting.

\section{Outcome Measure}

The Parents' Evaluation of Developmental Status (PEDS) was used to screen infants for risk of developmental and/ or behavioral problems [21]. The PEDS can be used from birth to 8 years of age and is written at a grade 4 to 5 reading level. Validity and reliability has been determined through assessment of more than 771 children in various settings across the US including physician offices, outpatient clinics, day care centers, and schools. In addition, the 
PEDS has been standardized on 2823 families from a range of economic and ethnic backgrounds.

The PEDS is a 10 item parent report screening measure designed to facilitate parent-professional communication about development and to increase the probability that developmental and behavioral problems in children, birth to 8 years of age, are detected and addressed. This is accomplished by eliciting parental concerns, determining a child's level of risk for problems, and identifying the appropriate next steps. The PEDS classifies children into one of five categories or 'Paths' based on parents' report of concerns: (A) multiple significant concerns are present that are predictive of disability (high risk); (B) one significant concern is present that is predictive of disability (moderate risk); (C) nonsignificant concerns are present that are not predictive of disability but there is elevated risk for behavioral problems (including mental health problems) because of disruption of family functioning, parent-child conflict and/or disciplinary problems (moderate - low risk); (D) parents have problems communicating (moderate risk); or (E) no concerns are present (extremely low - no risk). The PEDS has a sensitivity and specificity that ranges between $70 \%$ and $80 \%$, and these percentages increase with repeated administration [21].

\section{Independent Variables}

Potential covariates of interest were grouped into four categories: child characteristics, home environment, sociodemographic factors, and pregnancy-related variables.

\section{Child Characteristics}

Child health status was based on maternal report (excellent, good, fair, poor, or terrible) and on change in the child's health compared to 1 year ago (about the same, better, or worse). Caregivers reported on health care utilization, routine health examinations, immunizations, having a family doctor, chronic conditions, vision and hearing problems, and referrals.

\section{Home Environment Characteristics}

Maternal physical and emotional health status was based on self report (excellent, good, fair, poor, or terrible) [22]. Questions about abuse, social support, and relationship with a partner were asked. Information about parenting was collected and included parenting morale, which was assessed using the Parenting Morale Index [23], and parenting style, which was assessed using two subscales of the National Longitudinal Survey of Children and Youth (hostile/ineffective and aversion) [24].

\section{Sociodemographic Factors}

Self-reported information on marital status, education, annual household income, ethnicity, and lifestyle factors (smoking, alcohol, drug use) was collected.

\section{Pregnancy-Related Variables}

Several variables measured during the original randomized controlled trial were included in this analysis, including the Kellner Symptom Questionnaire [25], Rosenberg Self Esteem [26], McCubbin Social Support Index [27], Woman Abuse Screening Tool (WAST) [28], Edinburgh Postnatal Depression Scale [29] and Vaux Network Orientation Scale [30].

\section{Statistical Analysis}

Data collected from the follow-up study were linked to data from both the original randomized controlled trial using unique research identifiers (to include pregnancyrelated variables in the analysis) and to provincial perinatal records (to obtain the most accurate estimate of gestational age of the infant at birth). This resulted in data for mothers at four time points from their first trimester to 3 years post partum.

Bivariate comparisons between the PEDS path and independent variables in the four categories of interest were conducted using a chi-squared test. A multinomial logistic regression model was constructed to explore the relationship between risk of developmental problems and factors associated with this risk, yielding odds ratios and 95\% confidence intervals. Statistical significance was set at $\mathrm{p}<$ 0.05 for bivariate analyses and was also the criteria for considering variables for regression modeling along with known confounders. Selected predicted probabilities for screening in each PEDS path were also calculated. All statistical analyses were performed using Stata 9/SE version 9.2 .

\section{Results \\ Study Response and Demographics}

The results of the original randomized control trail indicated that additional support provided by nurses, or nurses and home visitors, could increase the number of women who use existing community based resources and increase the amount of information women obtain about pregnancy related topics. However, rates of alcohol and tobacco use, post partum depression and birth outcomes did not differ by group. The type of prenatal care a women obtained in the original trial was not a predictor of the PEDS score $(\mathrm{p}=0.737)$ and was not controlled for in subsequent analysis.

Mothers from the original trial who could be contacted and agreed to participate $(\mathrm{N}=791)$ represented $69 \%$ of those eligible $(\mathrm{N}=1147)$ (Figure 1$)$. Characteristics of mothers and their children at the time of the follow up study are described in Table 1 and reflect a middle income community in a large urban setting. Mothers who could not be contacted or refused to participate were more likely to be less than 25 years old ( $14 \%$ vs. $9 \%, p=0.012)$, non- 
Table I: Characteristics of mothers and children who participated in the follow up study

\begin{tabular}{|c|c|c|}
\hline Characteristic & $\begin{array}{r}\mathbf{N}=791 \\
n\end{array}$ & $\%$ \\
\hline \multicolumn{3}{|l|}{ MOTHERS } \\
\hline Married/Common law & 746 & 94.4 \\
\hline \multicolumn{3}{|l|}{ Education } \\
\hline High school or lower & 124 & 15.7 \\
\hline College/university/trade & 588 & 74.3 \\
\hline Post graduate studies & 79 & 10.0 \\
\hline \multicolumn{3}{|l|}{ Household income per year } \\
\hline$<\$ 40,000$ & 65 & 8.8 \\
\hline$\$ 40,000-\$ 80,000$ & 267 & 36.0 \\
\hline$>\$ 80,000$ & 410 & 55.3 \\
\hline Caucasian ethnicity & 668 & 84.5 \\
\hline Any smoking in the past month & 98 & 12.5 \\
\hline Any alcohol in the past month & 514 & 65.0 \\
\hline Any drugs in the past month & 17 & 2.2 \\
\hline $\begin{array}{l}\text { Excellent or good rating of physical health } \\
\text { in the past } 6 \text { months }\end{array}$ & 599 & 75.8 \\
\hline $\begin{array}{l}\text { Excellent or good rating of emotional } \\
\text { health in the past } 6 \text { months }\end{array}$ & 588 & 74.3 \\
\hline $\begin{array}{l}2 \text { weeks or more of self reported } \\
\text { depression since infant born }\end{array}$ & 281 & 35.5 \\
\hline $\begin{array}{l}6 \text { months or more of self reported } \\
\text { depression since infant born }\end{array}$ & 96 & 12.2 \\
\hline $\begin{array}{l}\text { Edinburgh Post Partum Depression Score } \\
>10 \text { within } 4 \text { months of delivery }\end{array}$ & 54 & 8.17 \\
\hline $\begin{array}{l}\text { Edinburgh Post Partum Depression Score } \\
>13 \text { within } 4 \text { months of delivery }\end{array}$ & 20 & 3.03 \\
\hline $\begin{array}{l}\text { Ever seen or witnessed abuse since child } \\
\text { was born }\end{array}$ & 105 & 13.3 \\
\hline $\begin{array}{l}\text { Mother has been abused since child was } \\
\text { born }\end{array}$ & 50 & 6.3 \\
\hline \multicolumn{3}{|l|}{ CHILDREN } \\
\hline Age $\geq 3$ years & 468 & 59.2 \\
\hline Male & 383 & 48.4 \\
\hline Born preterm (< 37 weeks) & 49 & 6.6 \\
\hline Child has regular family doctor & 750 & 94.9 \\
\hline $\begin{array}{l}\text { A parent stayed home with the child for } \\
\geq 24 \text { months }\end{array}$ & 320 & 40.5 \\
\hline Child has had routine health exam & 711 & 90.1 \\
\hline Child's immunization shots are up to date & 742 & 94.0 \\
\hline \multicolumn{3}{|l|}{ Child's current general health* } \\
\hline Excellent/Good & 731 & 92.4 \\
\hline Fair/Poor/Terrible & 60 & 7.6 \\
\hline $\begin{array}{l}\text { Child received non-parental care for }>20 \\
\text { hours per week in the past } 6 \text { months }\end{array}$ & 481 & 60.8 \\
\hline Parent reads to child once or more per day & 696 & 88.2 \\
\hline
\end{tabular}

Note: Denominator varies due to missing data

$*$ as rated by the child's mother

Caucasian $(25 \%$ vs. $16 \%, \mathrm{p}<0.001)$, smoke during pregnancy $(25 \%$ vs. $16 \%, p=0.001)$, have required food bank support ( $6 \%$ vs. $3 \%, \mathrm{p}=0.035)$, scored low on scales that assess ability to seek help (36\% vs. $29 \%, \mathrm{p}=0.009)$ and to have scored low on self esteem during pregnancy $(30 \%$ vs. $23 \%, \mathrm{p}=0.010$ ) compared to those mothers who completed the questionnaire.

\section{Child Development Screening Results}

Based on the PEDS, $11 \%(n=86)$ of children screened at high risk (Path $A)$ and $30 \%(n=239)$ screened at moderate risk (Path B) of developmental problems. Twenty four percent screened $(n=186)$ at an elevated risk for behavioral problems and/or mental health problems (Path C). There were no children who screened at moderate risk because their parents had problems communicating (Path D). Thirty five percent $(n=280)$ of children screened were not at risk for either developmental or behavioral problems (Path E). Mothers reported concerns with expressive language for $81 \%$ of children at high risk of developmental problems (Path A) and for $58 \%$ of children at moderate risk of developmental problems (Path B). Mothers also reported behavioral concerns in over half of the children identified at high and moderate risk of developmental problems (Paths A and B) and in $68 \%$ of children identified at elevated risk for behavioral and/or mental health problems (Path C).

Among the 86 children who screened at high risk of developmental problems, $43 \%(n=37)$ had previously been referred for further assessment. High risk children most likely to have received a referral had been born preterm $(15 \%$ vs. $0 \%)$, had previously had their hearing tested ( $70 \%$ vs. $31 \%)$, and had vision problems ( $11 \%$ vs. $0 \%$, all $\mathrm{p}<0.05$, Table 2).

The chi squared analysis suggested that children at high risk of developmental problems (Path A) were significantly more likely to be male, to have had ear infections (and hearing tests) and to have parents who reported improved child health compared to a year ago (all p < 0.05 , Table 3 ). The most common referral was to a speech and language pathologist and rates of referral increased as children screened at greater risk $(\mathrm{p}<0.001)$. Children who screened at high risk for developmental problems (Path A) were more likely to come from a single parent family and/or lower income homes $(p<0.014)$. Their mothers were also more likely to report a history of depression (36\%), abuse prior to pregnancy $(47 \%)$, distress during pregnancy (45\%), and more than 2 weeks of depression in the post partum period $(47 \%$, all $\mathrm{p}<0.05)$. In addition, they were more likely to report tension in their marital relationship $(56 \%, \mathrm{p}<0.004)$ and less likely to report that their families ate meals together on a daily basis $(74 \%, \mathrm{p}<0.014$, Table 3$)$. Mothers of children at high risk for developmental problems were also less likely to report high parenting morale $(\mathrm{p}<0.05)$.

Among children who screened at risk of behavioral and/ or mental health problems (Path C), $41 \%$ had mothers 
Table 2: Characteristics of children who had a referral compared to those who did not, among children screened at high risk of developmental problems (Path A)

\begin{tabular}{|c|c|c|c|}
\hline Characteristic & $\begin{array}{c}\text { Referral } \\
\mathbf{N}=\mathbf{3 7} \\
\text { n (\%) }\end{array}$ & $\begin{array}{c}\text { No referral } \\
N=49 \\
n(\%)\end{array}$ & p-value \\
\hline Age $\geq 3$ years & $22(59)$ & $34(61)$ & 0.339 \\
\hline Born preterm & $5(15)$ & $0(0)$ & 0.006 \\
\hline Male & $28(76)$ & $32(65)$ & 0.300 \\
\hline Child has regular family doctor & $34(92)$ & $43(88)$ & 0.726 \\
\hline Child has had routine health exam & $34(92)$ & $46(94)$ & 1.000 \\
\hline Child's immunization shots are up to date & $35(95)$ & $44(90)$ & 0.694 \\
\hline Child has had ear infections prior to age 2 & $24(65)$ & $22(45)$ & 0.066 \\
\hline Child has had hearing tested & $26(70)$ & $15(31)$ & $<0.001$ \\
\hline Child has vision problems & $4(\mathrm{II})$ & $0(0)$ & 0.031 \\
\hline \multicolumn{4}{|l|}{ Child's current general health* } \\
\hline Excellent/Good & $28(76)$ & $45(92)$ & 0.065 \\
\hline Fair/Poor/Terrible & $9(24)$ & $4(8)$ & \\
\hline \multicolumn{4}{|l|}{ Compared to I year ago, child's health is: } \\
\hline About the same & $17(46)$ & $32(65)$ & 0.191 \\
\hline Better & $18(49)$ & $16(33)$ & \\
\hline Worse & $2(5)$ & I (2) & \\
\hline Child has/had congenital abnormality & $2(5)$ & I (2) & 0.575 \\
\hline Child has/had chronic breathing problems & $6(16)$ & $4(8)$ & 0.249 \\
\hline Child has/had allergies & $6(16)$ & $3(6)$ & 0.165 \\
\hline Child has/had eczema or psoriasis & $7(19)$ & $14(29)$ & 0.302 \\
\hline Child has/had sleep problems & I (3) & $0(0)$ & 0.430 \\
\hline Low parenting morale & 7 (19) & $8(16)$ & 0.754 \\
\hline Hostile/Ineffective parenting (cut at $10^{\text {th }}$ percentile) & $4(11)$ & $13(27)$ & 0.101 \\
\hline
\end{tabular}

Note: Denominator varies due to missing data

who reported post partum depression, and 37\% had mothers who reported abuse prior to pregnancy (Table 3 ). Children who screened at risk of behavioral problems were significantly more likely to have a mother who was single and who had changed partners since the child was born, however, numbers were small $(\mathrm{p}<0.03)$.

Among 219 children who had their hearing tested, 12.8\% were tested due to repeat ear infections and $19.6 \%$ were tested due to suspected deafness. Children who were referred to a speech language pathologist were significantly more likely to have had their hearing tested ( $\mathrm{p}<$ 0.001 ). Among the 60 children who had been recommended for speech and language therapy, 43 (73\%) had their hearing tested of which 9 were assessed due to chronic ear infections. About $50 \%$ of those referred to speech and language assessment had had at least one ear infection before two years of age.

Multinomial logistic regression analysis revealed that the most significant predictors of screening at high risk (Path A) compared to low risk of developmental problems included male gender, having a history of ear infections prior to age two, a mother with a history of abuse, or a mother with low scores on contentment and relaxation during pregnancy with odds ratios ranging from 1.9 to 3.3
(Table 4). Male gender (Odds Ratio 1.6, 95\%, Confidence Interval 1.1-2.3) and low scores on contentment and relaxation during pregnancy (OR 1.5, 95\%, CI 1.0-2.2) increased the odds of screening at moderate risk of developmental problems (Path B) (Table 4). Children who screened at risk of behavioral and/or mental health problems (Path C) were more likely to have mothers who had experienced two or more weeks of post partum depression (OR 1.6, 95\% CI 1.1-2.4) and who had experienced abuse (OR 1.0, 95\% CI 1.0-2.3) (Table 4).

Based on the logistic regression model, a male infant with a history of ear infections, who had a mother with a history of abuse, low scores on relaxation during pregnancy, and at least two weeks of depression post partum had a predicted probability of 53\% for screening at high risk of developmental problems (Path A) (Table 5). A similar child, whose only difference was having a mother with a positive history of well-being, had a predicted probability of $19 \%$ for screening at high risk of developmental problems. The predicted probability of risk for developmental problems based on child and maternal characteristics is further illustrated in Table 5. 
Table 3: Characteristics of children and their environment for children in each risk category

\begin{tabular}{|c|c|c|c|c|c|}
\hline & $\begin{array}{c}\text { Path A } \\
\text { (high risk of } \\
\text { developmental problems) }\end{array}$ & $\begin{array}{c}\text { Path B } \\
\text { (moderate risk of } \\
\text { developmental problems) }\end{array}$ & $\begin{array}{c}\text { Path C } \\
\text { (elevated risk of behavioral } \\
\text { and/or mental health }\end{array}$ & $\begin{array}{c}\text { Path E } \\
\text { (extremely low to no risk) }\end{array}$ & \\
\hline & $\begin{array}{l}n(\%) \\
N=86\end{array}$ & $\begin{array}{c}n(\%) \\
N=239\end{array}$ & $N^{n}=186$ & $\begin{array}{c}n(\%) \\
N=280\end{array}$ & p-value \\
\hline \multicolumn{6}{|l|}{$\begin{array}{l}\text { Child's health history and current } \\
\text { health }\end{array}$} \\
\hline Male infant & $60(70)$ & $124(52)$ & $88(47)$ & III (40) & $<0.001$ \\
\hline Ear infections prior to age 2 & $46(53)$ & $90(39)$ & $68(37)$ & $96(35)$ & 0.018 \\
\hline Child has problems with vision & $4(5)$ & $8(3)$ & $6(3)$ & $8(3)$ & 0.846 \\
\hline \multicolumn{6}{|l|}{ Child's current general health } \\
\hline Excellent/Very good & $73(85)$ & $215(90)$ & $177(95)$ & $266(95)$ & 0.003 \\
\hline Fair/Poor/Terrible & $13(15)$ & $24(10)$ & $9(5)$ & $14(5)$ & \\
\hline \multicolumn{6}{|l|}{$\begin{array}{l}\text { Compared to I year ago, child's health } \\
\text { is*: }\end{array}$} \\
\hline About the same & $49(57)$ & $170(7 \mathrm{I})$ & $14 \mid(76)$ & $219(78)$ & 0.007 \\
\hline Better & $34(40)$ & $62(26)$ & $38(20)$ & $55(20)$ & \\
\hline Worse & $3(3)$ & $7(3)$ & $7(4)$ & $6(2)$ & \\
\hline Preterm delivery & $5(6)$ & $15(7)$ & $16(9)$ & $13(5)$ & 0.388 \\
\hline \multicolumn{6}{|l|}{ Child's health care } \\
\hline \multicolumn{6}{|l|}{ Child has been referred to: } \\
\hline Early intervention program & $8(9)$ & $7(3)$ & $2(1)$ & I (I) & $<0.001$ \\
\hline Speech and language pathologist & $21(35)$ & $30(13)$ & $3(2)$ & $6(2)$ & $<0.001$ \\
\hline Child developmental pediatrician & $8(9)$ & $7(3)$ & $3(2)$ & $4(1)$ & 0.005 \\
\hline Psychologist & $3(3)$ & $2(1)$ & $0(0)$ & $0(0)$ & 0.003 \\
\hline Physiotherapist & $7(8)$ & $8(3)$ & $3(2)$ & $9(3)$ & 0.071 \\
\hline Child has had any referral & $37(43)$ & $58(24)$ & $22(12)$ & $35(13)$ & $<0.001$ \\
\hline Child has had hearing tested & $41(48)$ & $67(28)$ & $58(31)$ & $53(19)$ & $<0.001$ \\
\hline $\begin{array}{l}\text { Child has had hearing tested due to } \\
\text { repeat or chronic ear infection }\end{array}$ & $11(27)$ & $6(9)$ & $5(9)$ & $6(11)$ & 0.028 \\
\hline Hearing tested due to suspected deafness & $15(39)$ & $14(21)$ & $6(10)$ & $8(15)$ & 0.006 \\
\hline \multicolumn{6}{|l|}{ Mother's demographics and lifestyle } \\
\hline \multicolumn{6}{|l|}{ Marital Status } \\
\hline Married/Common-law & $79(92)$ & $229(96)$ & $173(94)$ & $265(95)$ & 0.014 \\
\hline Separated/Divorced & $2(2)$ & $6(3)$ & $2(1)$ & $12(4)$ & \\
\hline Single & $5(6)$ & $4(2)$ & $10(5)$ & $3(1)$ & \\
\hline Age $<25$ years & $2(2)$ & II (5) & $13(7)$ & $9(3)$ & 0.217 \\
\hline Working at paid job & $52(61)$ & $142(59)$ & $104(57)$ & $184(66)$ & 0.220 \\
\hline Education is high school or lower & $18(21)$ & $40(17)$ & $28(15)$ & $38(14)$ & 0.393 \\
\hline \multicolumn{6}{|l|}{ Current household income per year } \\
\hline$<\$ 40,000$ & $13(16)$ & $19(8)$ & $15(8)$ & $18(7)$ & 0.014 \\
\hline$\$ 40,000-\$ 80,000$ & $35(43)$ & $85(37)$ & $68(40)$ & $79(30)$ & \\
\hline$>\$ 80,000$ & $34(4 I)$ & $123(54)$ & $89(52)$ & $164(63)$ & \\
\hline \multicolumn{6}{|l|}{$\begin{array}{l}\text { Mother's mental and emotional } \\
\text { health history }\end{array}$} \\
\hline History of depression prior to pregnancy & $31(36)$ & $49(20)$ & $36(19)$ & $56(20)$ & 0.009 \\
\hline Witnessed abuse prior to pregnancy* & $46(53)$ & $86(36)$ & $76(4 I)$ & $98(35)$ & 0.014 \\
\hline History of abuse prior to pregnancy* & $40(47)$ & $80(33)$ & $68(37)$ & $73(26)$ & 0.003 \\
\hline $\begin{array}{l}\text { Poor network orientation during } \\
\text { pregnancy }\end{array}$ & $6(7)$ & $4(2)$ & $10(5)$ & $6(2)$ & 0.024 \\
\hline Feelings of distress during pregnancy & $39(45)$ & $77(32)$ & $66(35)$ & $82(29)$ & 0.043 \\
\hline $\begin{array}{l}\text { Feelings of contentment, relaxation, and } \\
\text { well-being during pregnancy }\end{array}$ & $43(50)$ & $155(65)$ & $139(75)$ & $207(74)$ & $<0.001$ \\
\hline \multicolumn{6}{|l|}{$\begin{array}{l}\text { Mother's mental and emotional } \\
\text { health post partum }\end{array}$} \\
\hline $\begin{array}{l}\text { Edinburgh Post Partum Score }>10 \text { within } \\
\text { first } 4 \text { months }\end{array}$ & $9(12)$ & $17(9)$ & $12(8)$ & $16(7)$ & 0.523 \\
\hline $\begin{array}{l}\text { Edinburgh Post Partum Score }>13 \text { within } \\
\text { first } 4 \text { months }\end{array}$ & 3(4) & $8(4)$ & $4(3)$ & $5(2)$ & 0.659 \\
\hline$\geq 2$ weeks of depression since infant born & $40(47)$ & $84(35)$ & $76(4 I)$ & $81(29)$ & 0.007 \\
\hline $\begin{array}{l}\text { Rating of current physical health is fair/ } \\
\text { poor/terrible }\end{array}$ & $30(35)$ & $61(26)$ & $41(22)$ & $59(21)$ & 0.058 \\
\hline $\begin{array}{l}\text { Rating of current emotional health is fair/ } \\
\text { poor/terrible }\end{array}$ & $29(34)$ & $62(26)$ & $49(26)$ & $63(23)$ & 0.217 \\
\hline $\begin{array}{l}\text { Currently some tension in relationship } \\
\text { with partner }\end{array}$ & $45(56)$ & $92(40)$ & $64(36)$ & $92(34)$ & 0.004 \\
\hline
\end{tabular}


Table 3: Characteristics of children and their environment for children in each risk category (Continued)

\begin{tabular}{|c|c|c|c|c|c|}
\hline $\begin{array}{l}\text { Rating of current social support is fair/ } \\
\text { poor/terrible }\end{array}$ & $13(15)$ & $26(11)$ & $22(12)$ & $29(10)$ & 0.670 \\
\hline \multicolumn{6}{|l|}{ Parenting } \\
\hline High Parenting Morale & $71(83)$ & $215(90)$ & $167(90)$ & $262(94)$ & 0.024 \\
\hline $\begin{array}{l}\text { Parent reads to child once or more per } \\
\text { day }\end{array}$ & $74(86)$ & $211(88)$ & $164(89)$ & $247(89)$ & 0.930 \\
\hline $\begin{array}{l}\text { Family eats I or more meals together } \\
\text { daily }\end{array}$ & $64(74)$ & $207(87)$ & 147 (79) & $240(86)$ & 0.014 \\
\hline
\end{tabular}

*Types of abuse could include any one of physical, emotional, sexual, financial abuse, or neglect

Note: Denominator varies due to missing data

\section{Discussion}

Over $90 \%$ of the children in this study had routine health exams, a family physician and current immunization status. Of these children $10 \%$ were identified by PEDS as being at high risk for developmental problems, however over half of them had not received a more detailed assessment by 3 years of age. High risk children most likely to have received a referral were identified by preterm delivery. This study highlights the need for implementation of effective developmental screening to ensure that all children at risk of developmental problems, not just those born preterm, have a similar probability of being identified and of receiving appropriate and timely early intervention.

The variables that were associated with an increased probability of referral in this study (preterm birth, had hearing tested, had vision problems) are medical in nature, but this study, of primarily middle and upper income families under a system of universal health care, shows that sociocultural variables have a significant relationship to the development of children. Those children most at risk of developmental problems were characterized by having mothers with a prenatal history of abuse, depression, distress and an unwillingness to access social support networks as well as fewer financial resources. In the postpartum period, children at risk could be identified by mothers with post partum depression and marital tension. Consequently, identification of children at risk of developmental problems could begin earlier by identifying mothers with poor emotional and social health in the prenatal and early post partum period.

The link between maternal depression, prenatal stress and child development is well established [31-34]. Postpartum depression has been associated with negative maternal attitudes and may adversely influence the motherinfant relationship, increasing the risk for delayed cogni-

Table 4: Multinomial logistic regression of infant and maternal characteristics for developmental delay screening status using the PEDS screening tool.

\begin{tabular}{|c|c|c|c|}
\hline Variable & Odds Ratio & 95\% C.I. & p-value \\
\hline \multicolumn{4}{|l|}{ Path A (high risk of developmental problems) } \\
\hline Male infant & 3.3 & $(1.9,5.8)$ & $<0.001$ \\
\hline Ear infections prior to age 2 & 1.9 & $(1.1,3.2)$ & 0.019 \\
\hline Household income $<\$ 40,000$ & 2.1 & $(0.9,4.8)$ & 0.071 \\
\hline Maternal history of abuse & 2.2 & $(1.3,3.7)$ & 0.006 \\
\hline Low scores on contentment/relaxation during pregnancy & 2.5 & $(1.4,4.2)$ & 0.001 \\
\hline 2 weeks of depression post partum & 1.7 & $(0.9,2.9)$ & 0.062 \\
\hline \multicolumn{4}{|l|}{ Path B (moderate risk of developmental problems) } \\
\hline Male infant & 1.6 & $(1.1,2.3)$ & 0.011 \\
\hline Ear infections prior to age 2 & 1.2 & $(0.8,1.7)$ & 0.434 \\
\hline Household income $<\$ 40,000$ & 1.2 & $(0.6,2.4)$ & 0.595 \\
\hline Maternal history of abuse & 1.3 & $(0.9,2.0)$ & 0.178 \\
\hline Low scores on contentment/relaxation during pregnancy & 1.5 & $(1.0,2.2)$ & 0.055 \\
\hline 2 weeks of depression post partum & 1.2 & $(0.8,1.8)$ & 0.333 \\
\hline \multicolumn{4}{|c|}{ Path C (elevated risk of behavioral and/or mental health problems) } \\
\hline Male infant & 1.3 & $(0.9,2.0)$ & 0.167 \\
\hline Ear infections prior to age 2 & 1.1 & $(0.7,1.7)$ & 0.655 \\
\hline Household income $<\$ 40,000$ & 1.2 & $(0.6,2.5)$ & 0.635 \\
\hline Maternal history of abuse & 1.5 & $(1.0,2.3)$ & 0.060 \\
\hline Low scores on contentment/relaxation during pregnancy & 0.9 & $(0.6,1.5)$ & 0.845 \\
\hline 2 weeks of depression post partum & 1.6 & $(1.1,2.4)$ & 0.025 \\
\hline
\end{tabular}

Note: Path E (extremely low to no risk) is the comparison (baseline) group 
Table 5: Predicted probability for each PEDS path from the multinomial logistic regression model.

\begin{tabular}{|c|c|c|c|c|c|c|c|}
\hline \multicolumn{2}{|c|}{ Infant characteristics } & \multicolumn{2}{|c|}{ Environment } & \multicolumn{4}{|c|}{ Predicted Probability of Screening in Each PEDS Path } \\
\hline Gender & Ear infections & $\begin{array}{l}\text { Household } \\
\text { income }\end{array}$ & $\begin{array}{l}\text { Mother with a history of } \\
\text { abuse, postpartum } \\
\text { depression, and poor } \\
\text { contentment during } \\
\text { pregnancy }\end{array}$ & $\begin{array}{c}\text { Path A } \\
\text { (high risk of } \\
\text { developmental } \\
\text { problems) }\end{array}$ & $\begin{array}{c}\text { Path B } \\
\text { (moderate risk of } \\
\text { developmental } \\
\text { problems) }\end{array}$ & $\begin{array}{c}\text { Path C } \\
\text { (elevated risk of } \\
\text { behavioral and/or } \\
\text { mental health } \\
\text { problems) }\end{array}$ & $\begin{array}{c}\text { Path E } \\
\text { (extremely low to } \\
\text { no risk) }\end{array}$ \\
\hline Male & Ear infections & Low income & History & 0.53 & 0.23 & 0.15 & 0.09 \\
\hline Male & Ear infections & High income & None & 0.11 & 0.32 & 0.22 & 0.35 \\
\hline Male & Ear infections & Low income & None & 0.19 & 0.32 & 0.21 & 0.28 \\
\hline Male & None & Low income & None & 0.12 & 0.32 & 0.22 & 0.33 \\
\hline Female & None & High income & None & 0.03 & 0.25 & 0.22 & 0.50 \\
\hline Female & None & High income & History & 0.12 & 0.33 & 0.27 & 0.28 \\
\hline Female & Ear infections & High income & None & 0.04 & 0.27 & 0.22 & 0.47 \\
\hline Female & Ear infections & Low & None & 0.08 & 0.28 & 0.23 & 0.41 \\
\hline
\end{tabular}

tive development and child behavior problems [35-37]. It can also interfere with parenting self-efficacy, parenting skills and marital satisfaction for both partners [38-40]. From this study, a male infant with ear infections, a low income environment, and a mother with a history of psychosocial risk (e.g. history of abuse, postpartum depression, and poor contentment during pregnancy) had a $53 \%$ chance of screening at high risk for developmental problems. If there was an absence of psychosocial risk during pregnancy and post partum, this same child would have had a reduction in the likelihood of screening at the same level of risk by over 30\%.

Although this study provided a unique opportunity to examine prenatal, post natal and current variables associated with child health and development at age 3, the data are limited in that women who could not be reached at follow up were younger, had lower self esteem and fewer financial resources. Consequently our findings may be best generalized to women over age 25 and families with middle or higher incomes. Furthermore, although the PEDS has a reported sensitivity and specificity of about $80 \%$, which is considered good given the nature and complexity of child development [41], telephone administration of the PEDS has not been well researched. Preliminary findings suggest that the telephone PEDS is reliable but may have reduced sensitivity to identify parents concerns resulting in underestimation of risk [42]. Consequently, the combination of loss in the follow up of our more vulnerable mothers and the use of telephone follow up suggest our estimates of risk of developmental problems may be conservative.

\section{Conclusion}

This study indicates that there are missed opportunities for the screening and identification of children at high risk of developmental problems who may benefit from further assessment. Ethical implications of putting effective standard screening into practice would necessitate follow- up resources and processes, including assessments for approximately twice as many children as are currently being seen, as well as appropriate, readily available, evidence based, early intervention programs [43]. The structural, economic and community resources necessary for ethical screening would require planning and organization, including training and recruitment of speech language technologists and specialists.

Developmental risk for some children may be identified very early by prenatal maternal characteristics such as history of abuse or depression, lack of contentment and wellbeing, and low annual family income. Prenatal intervention could occur for families that screen at-risk with a focus on maternal mental health and early parenting support. The goal would be the reduction of risk for developmental problems in children in the preschool years. Indeed, the reduction in probability of screening at risk for male infants from $53 \%$ to $19 \%$ through attention to maternal mental health, with no change in economic circumstance, provides a compelling incentive to address issues of well being, social support and early identification of poor mental health. Attention to antecedent events is in alignment with a Population Health Approach and with the United Nations Convention on the Rights of the Child $[44,45]$. Furthermore, improving maternal mental health and supports for parenting may have positive influence beyond the index child with regard to improved outcomes for other children in the home and improved marital relations. Based on this, we are implementing a research project that investigates the impact of reorienting prenatal care to address mental health and social support. Ultimately, effective screening of child development in combination with a comprehensive assessment of all aspects of maternal health would increase the detection of children at highest risk of developmental problems who would benefit from early intervention and support for the health of their families. 


\section{Competing interests}

The authors declare that they have no competing interests.

\section{Authors' contributions}

SCT conceived of the study and supervised all aspects of its implementation. JES completed the analyses. DWJ managed study implementation and data collection. KB, $\mathrm{SL}$, and DC, contributed to development of the survey instrument and interpretation of findings. All authors helped to conceptualize ideas, interpret findings, and review and revise drafts of the manuscript. All authors read and approved the final manuscript.

\section{Acknowledgements}

This study was funded by the Calgary Children's Initiative and the Calgary Health Region. SCT received salary support from the Alberta Heritage Foundation for Medical Research. We would like to gratefully acknowledge the support, assistance, and enthusiasm of Calgary Children's Initiative, in particular, Lori Friesen, Donna McLeod, and Varina Russell and members of the "Zero to Five" Working Group; Carrie Collins, Calgary Health Region; Heather Davey, Calgary Health Region; Women and Children's Health portfolio of the Calgary Health Region. In addition, we appreciate the contributions of the Population Research Laboratory, University of Alberta, and Dr. Francis Glascoe and her team, Vanderbilt University, for their interest and enthusiasm in regards to the Parents' Evaluation of Developmental Status (PEDS). We would also like to acknowledge the editorial assistance of Monica Jack, Alberta Centre for Child, Family and Community Research, and Sarah Horn, Calgary Health Region in preparation of this manuscript.

\section{References}

I. Rydz D, Shevell MI, Majnemer A, Oskoui M: Developmental screening. Journal of Child Neurology 2005, 20:4-2I.

2. Boyle CA, Decoufle P, Yeargin-Allsopp M: Prevalence and health impact of developmental disabilities in US children. Pediatrics 1994, 93:399-403.

3. Ministerial Council on Education E Training and Youth Affairs: National Report on Schooling in Australia. 2000.

4. K B, Tough S, Edwards N, Rotstein K, Johnson M, Marokus B, Bowen G, Donnelly C: CUPS One World Child Development Centre: A Multiple Intervention Preschool Program for Children Living in Extreme Poverty. 2006 [http://www.ucalgary.ca/nu/files/ CUPSOneWorld2004-05Report September5 06.pdf].

5. The Effectiveness of Early Intervention for At-Risk and Handicapped Children Edited by: MJ G and Bennett FC. New York, Academic Press; 1987.

6. Glascoe FP: Using parents' concerns to detect and address developmental and behavioral problems. Journal of the Society of Pediatric Nurses 1999, 4:24-35.

7. Guralnick MJ: Effectiveness of early intervention for vulnerable children: a developmental perspective. American Journal of Mental Retardation 1998, 102:319-345.

8. To T, Guttmann A, Dick PT, Rosenfield JD, Parkin PC, Tassoudji M, Vydykhan TN, Cao H, Harris JK: Risk markers for poor developmental attainment in young children: results from a longitudinal national survey. Archives of Pediatrics \& Adolescent Medicine 2004, 158:643-649.

9. Disabilities CC: Developmental surveillance and screening of infants and young children. Pediatrics 200I, 108:192-196.

10. Williams J, Holmes CA: Improving the early detection of children with subtle developmental problems. Journal of Child Health Care 2004, 8:34-46.

II. Dworkin PH: Developmental screening: (still) expecting the impossible? Pediatrics 1992, 89:| 253-1255.

12. Sices L, Feudtner C, McLaughlin J, Drotar D, Williams M: How do primary care physicians identify young children with devel- opmental delays? A national survey. Journal of Developmental \& Behavioral Pediatrics 2003, 24:409-4I7.

13. Halfon N, Hochstein M, Sareen H, O'Connor KG, Inkelas M, Olson LM: Barriers to the provision of developmental assessments during pediatric health supervision. 200I [http://www.aap.org/ research/periodicsurvey/ps46pas4.htm]. Presented at the Pediatric Academic Societies annual meeting, May 200I, Periodic Survey of Fellows, American Academy of Pediatrics, Division of Health Policy Research

14. Glascoe FP: A method for deciding how to respond to parents' concerns about development and behavior. Ambulatory Child Health 1999, 5:197-208.

15. Tervo RC: Parent's reports predict their child's developmental problems. Clin Pediatr (Phila) 2005, 44:60I-6II

16. Glascoe FP: The value of parents' concerns to detect and address developmental and behavioural problems. J Paediatr Child Health 1999, 35: I-8.

17. Sonnander K: Early identification of children with developmental disabilities. Acta Paediatrica Supplement 2000, 89:17-23.

18. Sameroff AJ, Seifer R, Barocas R, Zax M, Greenspan S: Intelligence quotient scores of 4-year-old children: social-environmental risk factors. Pediatrics 1987, 79:343-350.

19. Child Rearing in America: Challenges Facing Parents of Young Children Edited by: Halfon N, McLearn KT and Schuster MA. New York, Cambridge University Press; 2002.

20. Tough SC, Johnston DW, Siever J, Jorgenson G, Slocombe L, Lane C $M C$ : Does supplementary prenatal nursing and home visitation support improve resource utilization in a system of universal health care? Results from a randomized controlled trial in Canada. Birth 2006, 33:183-194.

21. Glascoe FP: Collaborating With Parents: Using Parents' Evaluation of Developmental Status (PEDS) to Detect and Address Developmental and Behavioral Problems Nashville, TN, Ellsworth \& Vandermeer; 2002.

22. Mah JK, Tough S, Fung T, Douglas-England K, Verhoef M: Parents' global rating of mental health correlates with SF-36 scores and health services satisfaction. Quality of Life Research 2006 15:|395-|40|.

23. Trute $B$, Hiebert-Murphy $D$ : Predicting family adjustment and parenting stress in childhood disability services using brief assessment tools. Journal of Intellectual \& Developmental Disability 2005, 30:217-225

24. Strayhorn JM, Weidman CS: A Parent Practices Scale and its relation to parent and child mental health. Journal of the American Academy of Child \& Adolescent Psychiatry 1988, 27:613-618.

25. Kellner R: A symptom questionnaire. J Clin Psychiatry 1987, 48:268-274

26. Rosenberg MJ: Society and the Adolescent Self-Image Revised edition. Middletown, CT, Wesleyan University Press; 1989.

27. McCubbin HI, Patterson J, Glynn T: Social support index (SSI) (1 982). In Measures for Clinical Practice: A Sourcebook 3rd edition. Edited by: Corcoran K and Fischer J. New York, Free Press; 2000:446-447.

28. Brown JB, Lent B, PJ B, G S, L P: Development of woman abuse screening tool for use in family practice. Fam Med 1996, 28:422-428

29. Cox JL, Holden JM, Sagovsky R: Detection of postnatal depression: development of the 10-item Edinburgh Postnatal Depression Scale. Br J Psychiatry 1987, 150:782-786.

30. Vaux AC, Burda PC, Stewart D: Orientation toward utilization of support resources. J Community Psychol 1986, 14:159-170.

31. Gutteling BM, de Weerth C, Zandbelt N, Mulder EJH, Visser GH, Buitelaar JK: Does Maternal Prenatal Stress Adversely Affect the Child's Learning and Memory at Age Six? J Abnorm Child Psychol 2006, 34:789-798.

32. Knackstedt MK, Hamelmann E, Arck PC: Mothers in Stress: Consequences for the Offspring. Am J Reprod Immunol 2005, 54:63-69.

33. Wadhwa PD, Culhane JF, Rauh V, Barve SS: Stress and preterm birth: neuroendocrine, immune/inflammatory, and vascular mechanisms. Matern Child Health J 200I, 5: I 19-125.

34. O'Connor TG, Ben-Shlomo Y, Heron J, Golding J, Adams D, Glover V: Prenatal Anxiety Predicts Individual Differences in Cortisol in Pre-Adolescent Children. Biol Psychiatry 2005, 58:2 II-2I 7.

35. Porter CL, Hsu HC: First-time mothers' perceptions of efficacy during the transition to motherhood: links to infant temperament. Journal of Family Psychology 2003, 17:54-64. 
36. Grace SL, Evindar A, Stewart DE: The effect of postpartum depression on child cognitive development and behavior: a review and critical analysis of the literature. Archives of Women's Mental Health 2003, 6:263-274.

37. Robinson GE, Stewart DE: Postpartum disorders. In Psychological Aspects of Women's Health Care Second edition. Edited by: Stotland NL and Stewart DE. Washington, DC, American Psychiatric Press; 2001:117-139.

38. O'Hara MW, Neunaber DJ, Zekoski EM: Prospective study of postpartum depression: prevalence, course, and predictive factors. J Abnorm Psychol 1984, 93:158-171.

39. Burke $L$ : The impact of maternal depression on familial relationships. International Review of Psychiatry 2003, 15:243-255.

40. Whisman MA, Uebelacker LA, Weinstock LM: Psychopathology and marital satisfaction: the importance of evaluating both partners. Journal of Consulting \& Clinical Psychology 2004, 72:830-838.

41. Glascoe FP: Developmental screening. In Disorders of Development and Learning: A Practical Guide to Assessment and Management Edited by: Wolraich M. St Louis, MO, Mosby; 1996:89-128.

42. Ng W, Reynolds D, Kennedy E, Feightner K, Holowaty P, Wade K, Fleiszer P, Glascoe FP, Northrup D: Measuring the prevalence of children at risk for developmental problems using the Parents' Evaluation of Developmental Status (PEDS) in a telephone survey. Presented at the American Public Health Association 13th Annual Meeting, Boston, MA; 2006.

43. Strong K, Wald N, Miller A, Alwan A, Group WHOC: Current concepts in screening for noncommunicable disease: World Health Organization Consultation Group Report on methodology of noncommunicable disease screening. J Med Screen 2005, 1 2:12-19.

44. Assembly UNG: Convention on the Rights of the Child. 1989, 44/25:

45. Canada H, Chomik TA: The Population Health Template: Key Elements and Actions that Define a Population Health Approach. Ottawa, Health Canada; 2001.

\section{Pre-publication history}

The pre-publication history for this paper can be accessed here:

http://www.biomedcentral.com/1471-2393/8/16/prepub

\section{Publish with Bio Med Central and every scientist can read your work free of charge}

"BioMed Central will be the most significant development for disseminating the results of biomedical research in our lifetime. "

Sir Paul Nurse, Cancer Research UK

Your research papers will be:

- available free of charge to the entire biomedical community

- peer reviewed and published immediately upon acceptance

- cited in PubMed and archived on PubMed Central

- yours - you keep the copyright 